\title{
Relação entre servidores/as contratados/as e concursados/as em serviços da assistência social: impactos sobre o trabalho
}

\section{Relationships between hired and permanent civil servants in social work services: impacts on the work}

\author{
Fernanda de Jesus Ligeiro Braga (orcid.org/0000-0003-2796-7644)11 \\ Mariana Prioli Cordeiro (orcid.org/0000-0002-5523-5099)2 \\ Marcelo Afonso Ribeiro (orcid.org/0000-0002-0396-7693) ${ }^{3}$
}

\begin{abstract}
Resumo
A "terceirização" desponta na contemporânea morfologia do trabalho como uma das formas centrais de gestão institucional. No setor público brasileiro, a partir de relações público-privadas intensificadas após a contrarreforma do Estado em meados da década de 1990, modos de flexibilização dos vínculos empregatícios, dentre eles a "terceirização", surgem de modo a se tornar a regra na operacionalização de políticas sociais. Esta pesquisa objetivou analisar as relações de trabalho entre profissionais concursados/as e contratados/as em serviços de assistência social no município de São Paulo. Para isso, foram realizadas entrevistas semiestruturadas com profissionais contratados/as e concursados/as em CRAS, CREAS e NPJ's da cidade de São Paulo. Os principais resultados indicam que os/as trabalhadores/as destacaram a hierarquia, diferenças de tratamento, de salários e de benefícios entre profissionais contratados/as e concursados/as, bem como a predominância de relações de fiscalização e não de parceria como seria o esperado conforme documentos oficiais da política de assistência social.
\end{abstract}

Palavras-chave: Terceiro setor. Trabalho. Assistência social. Terceirização. Políticas públicas.

\begin{abstract}
"Outsourcing" emerges in the contemporary morphology of work as one of the central forms of institutional management. In the Brazilian public sector, from public-private relations intensified after the counter-reform of the State in the mid-1990s, ways of making employment bonds more flexible, including "outsourcing", arise in order to become the rule in the operationalization of social policies. This research aimed to analyze the work relationship between hired and permanent civil servants in social work services in the city of São Paulo. For this, semi-structured interviews were conducted with hired and permanent civil servants in CRAS, CREAS and NPJs in the city of São Paulo. The main results indicate that the workers highlighted the hierarchy, differences in treatment, salaries and

\footnotetext{
1 Universidade Federal de São Paulo, São Paulo, Brasil. E-mail: braga_fernanda@outlook.com.

2 Universidade de São Paulo, São Paulo, Brasil. E-mail: mpriolicordeiro@usp.br.

3 Universidade São Paulo, São Paulo, Brasil. E-mail: marcelopsi@usp.br.
} 
benefits between hired and permanent civil servants, as well as the predominance of supervisory relationship and not of partnership, as would be expected according to official documents of the social work policy.

Keywords: Third sector. Work. Social service. Outsourced services. Public policies.

A Carta Magna de 1988 consagrou um profundo avanço e apontou para a construção de "uma espécie de Estado de Bem-Estar Social” (Netto, 1999, p. 77), apoiado na pressão das lutas sociais e dos/as trabalhadores/as. Tal avanço, entretanto, ocorreu em um campo permeado por severas contradições, indo na contracorrente internacional. Afinal, na década de 1980, os países centrais - grande parte europeus - já colocavam em questão o próprio Welfare State - o Estado como responsável pelos problemas sociais e por promover serviços básicos e essenciais à população -, como consequência da consolidação da corrente neoliberal. Nesse sentido, no Brasil, a construção de políticas sociais pautadas na lógica de garantia de direitos pelo Estado foi seguida, lenta e gradualmente, pelo processo de reestruturação produtiva e pela contrarreforma do Estado brasileiro (Montaño, 2010). Tal processo contribui para justificar a contradição e o distanciamento entre o que está presente na legislação e o que é efetivamente realizado em termos de implementação e operacionalização das políticas sociais.

Assim, podemos dizer que o Brasil nunca vivenciou plenamente o Welfare State. Uma parte significativa de nossa população sempre viveu à margem das redes de proteção social oferecidas pelo Estado. Além disso, o acesso ao trabalho regulado e protegido sempre foi limitado, já que apenas uma parcela da população esteve inserida no mercado formal de trabalho. A precarização sempre foi, portanto, uma marca do trabalho da maioria dos/as brasileiros/as e, com o ajuste neoliberal, essa precariedade foi ampliada para segmentos da população, que tinham acesso a algum tipo de proteção (Cordeiro, Sato, \& Oliveira, 2019). Nesse processo,

o imperativo da flexibilidade transforma a produção e as relações de trabalho: os contratos temporários de curto prazo, intermitentes e ajustáveis às demandas das empresas, tornam-se o padrão. A terceirização de mão de obra é uma das estratégias que atendem ao imperativo da flexibilidade, pois permite que as empresas contratem trabalhadores na medida exata de suas necessidades, estas sempre variáveis, e transfiram para os trabalhadores as inseguranças e incertezas do mercado. (Cordeiro 
et al., 2019, p. 334, tradução nossa)

Sobretudo nas capitais brasileiras, as mudanças de gestão dos equipamentos públicos impulsionadas pela contrarreforma do Estado de Bresser Pereira, em 1995, geraram alterações legislativas - entre elas, a Lei $n^{\circ}$ 9.790/99 (Brasil, 1999) - bem como a criação de novas personalidades jurídicas - organizações sociais, fundações estatais de direito privado, organizações da sociedade civil de direito público-, com as quais o Estado estabeleceria "parcerias" para lidar com a "questão social". Parcerias estas que eram previstas na Constituição de 1988 em caráter complementar, mas que, após o processo de contrarreforma, de viés neoliberal, ganhou maior importância na execução de políticas sociais (Montaño, 2010).

As parcerias público-privadas acompanham boa parte da história das ações na assistência social. Afinal, elas remontam ao início do século XIX, quando o Estado transferiu a responsabilidade pelo cuidado de crianças e bebês abandonados às Santas Casas de Misericórdia, inaugurando aquilo que Mestriner (2008) chamou de "fase filantrópica da assistência social". A aprovação da Política Nacional de Assistência Social (PNAS), em 2004, e a implementação do Sistema Único de Assistência Social (SUAS), no ano seguinte, pareciam mudar essa relação. Afinal, as normativas da política colocaram a assistência social como um dever do Estado, reforçando o caráter apenas complementar das entidades privadas. No entanto, o SUAS nasce em meio à já consolidada contrarreforma do Estado. Assim, sob a justificativa de impedimentos fiscais e legais para a realização de concursos públicos, diversas prefeituras continuaram delegando a contratação de profissionais a organizações privadas e filantrópicas (Senra \& Guzzo, 2012). Em 2017, essas "parcerias" ganharam novos contornos, passando a ser reguladas pela Lei $\mathrm{n}^{\circ}$ 13.019/2014, mais conhecida como Marco Regulatório das Organizações da Sociedade Civil (MROSC) (Brasil, 2014).

O estabelecimento dessas parcerias favorece a manutenção de práticas e lógicas tradicionais, marcadas pelo assistencialismo, clientelismo e caridade. Afinal, muitas das organizações da sociedade civil (OSC) que, hoje, são conveniadas às secretarias municipais de assistência social são anteriores ao SUAS e mantêm práticas e posturas construídas ao longo de suas histórias, ainda que essas sejam incoerentes com alguns dos princípios da atual política de assistência social (Costa, 2016). Com isso, não estamos dizendo que todas as OSC que executam os serviços, programas e projetos do SUAS tenham essa postura. Afinal, tal como nos lembra 
Mestriner (2008), esse campo, "apesar dos comportamentos prevalentes, é diversificado e multifacetado, não se podendo fazer qualquer generalização ou estigmatização" (p. 49).

Tampouco podemos dizer que todos os municípios brasileiros estabelecem esse tipo de "parceria". Segundo o Censo SUAS 2017 (Brasil, 2018), em 2016, 37\% dos municípios fizeram transferência de recursos por convênio no âmbito da política de assistência social, sendo essas transferências mais frequentes nas regiões Sudeste $(60,6 \%)$ e Sul $(46,5 \%)$. O documento ainda expõe o percentual de trabalhadores/as vinculados/as às secretarias municipais de assistência social, revelando que $38 \%$ atuam sob o regime de trabalho estatutário; $10,8 \%$ são celetistas; $16,7 \%$ são comissionados/as e $34,5 \%$ possuem outros vínculos. Tendo em vista o contexto da cidade de São Paulo, local em que a pesquisa foi realizada, essa questão se torna mais significativa, uma vez que, segundo dados da Secretaria Municipal de Assistência e Desenvolvimento Social de São Paulo - SMADS (SMADS, 2020), a prefeitura mantém 1.233 convênios com 354 OSC. Isso corresponde a 93,12\% da composição da rede socioassistencial do município, visto que apenas 91 serviços são administrados diretamente pela prefeitura.

Nessa conjuntura, é importante frisar ao menos dois modelos de contratação: (1) Regime Estatutário, regulamentado pela Lei $\mathrm{n}^{\circ} 8.112 / 90$, de 11 de dezembro de 1990, em que os/as servidores/as são admitidos/as por meio de um concurso público e está associado à estabilidade do emprego (após os três anos de estágio probatório), direito a adicionais, licenças, gratificações, podendo também aproveitar benefícios da Consolidação das Leis do Trabalho (CLT). Neste texto, chamaremos os/as trabalhadores/as que possuem esse tipo de vínculo de "concursados/as"; e (2) Regime Celetista (regido pela CLT, Decreto-lei $n^{\circ} 5.452$ de $1^{\circ}$ de maio de 1943), em que os/as servidores/as têm direito a aviso prévio, multas rescisórias, férias, décimo terceiro, vale transporte e aposentadoria pelo Instituto Nacional de Seguro Social (INSS), de acordo com um teto estipulado. Em 2017, foram feitas importantes modificações na CLT, mas estas não foram aqui consideradas pelo fato de a pesquisa ter sido realizada em período anterior. Os/as trabalhadores/as que se enquadram nesse regime serão, aqui, chamados de "contratados/as".

No município de São Paulo, o/a estatutário/a é direcionado/a para atuar nos serviços da administração direta (Centros de Referência da Assistência Social - CRAS, Centros de Referência Especializados da Assistência Social - CREAS, Centros de Referência Especializados para População em Situação de Rua - Centro POP e Coordenação de Pronto Atendimento Social - CPAS). Os 
convênios com as OSC assumem praticamente todos os outros serviços da rede, sendo os contratos entre as organizações e seus/uas funcionários/as regidos pela CLT.

Apesar de também reconhecermos que há heterogeneidade dentro do próprio setor público quanto aos regimes de contratação, identificamos que se estabelecem dentro dos serviços públicos ao menos duas categorias de trabalhadores/as: servidores/as estatais (os/as "concursados/as"), tidos como representantes do poder público e os/as servidores/as não estatais (os/as "contratados/as"), que representam as organizações conveniadas e que, frequentemente, são identificados/as pelos/as próprios/as trabalhadores/as como "terceirizados/as". Os cargos comissionados que constituiriam outra categoria possível, apesar de não serem abordados nesta pesquisa, mereceriam um olhar aprofundado.

Como supracitado, a contrarreforma que ocorreu no Brasil no fim da década de 1990 impulsionou a criação de novas personalidades jurídicas que atuariam (ou não) como parceiras do Estado. Além disso, ela possibilitou a consolidação de formas de flexibilização do trabalho e dos direitos, caracterizando uma nova morfologia do trabalho (Antunes, 2005). Tal processo seguiu uma tendência internacional de profundas mudanças no mundo do trabalho e na vida social, caracterizadas por rupturas e fragilizações de suas estruturas tradicionais, bem como pela emergência de dinâmicas de trabalho mais fluídas (Antunes, 2012). Se, por um lado, isso permitiu a abertura para inovações, por outro, facilitou a precarização, instabilidade e insegurança, bem como uma maior responsabilização dos/as próprios/as trabalhadores/as por seu trabalho e sua carreira.

Como uma das formas de flexibilização, surge a "terceirização". Marcelino (2008) define "terceirização" como a relação de vínculo trabalhista na qual dada empresa/empregador contrata um terceiro para prestar serviços na mesma, sendo que tal associação é, geralmente, marcada por uma relação de trabalho vulnerável, pela fragilidade dos direitos trabalhistas, de defesa e segurança. No caso do SUAS, o "terceiro" são as Organizações da Sociedade Civil.

Faz-se necessário, aqui, fazer uma distinção importante tomando como referência Antunes (2012) e Lima e Curado (2017). A flexibilização tem sido tomada como panaceia para todos os problemas do desenvolvimento do capitalismo afirmando que, quanto maior controle do Estado, menor desenvolvimento possível e menor chance de evolução profissional pessoal, com base do ideário neoliberal. Esse movimento tende a beneficiar parte dos/as trabalhadores/as, 
principalmente aqueles/as com maior capital social, cultural e material, que, ao terem seu trabalho flexibilizado, recebem vantagens pela individualização e pela flexibilização, buscam autonomia e têm condição de consegui-la. Enquanto isso, os/as demais trabalhadores/as, correspondendo ao número maior de pessoas no mercado de trabalho no Brasil, tendem a necessitar de maior suporte do Estado e da organização/instituição contratante, e têm dificuldade de se individualizar e flexibilizar, o que pode gerar uma situação de precarização. Em síntese, flexibilização e precarização são resultantes distintas do mesmo processo, dependendo do quantum de capital que o/a trabalhador/a possui e quanto pode, ou não, ter seu trabalho individualizado com menor suporte do/a contratante. A "terceirização" é um dos mecanismos de flexibilização do trabalho e pode gerar as duas resultantes, por isso localizar quem é o/a terceirizado/a auxilia na análise dos efeitos do processo de "terceirização".

Um estudo da Secretaria Nacional de Relações de Trabalho e do Departamento Intersindical de Estatística e Estudos Socioeconômicos (2014) indica que trabalhadores/as "terceirizados/as", em geral, têm remuneração média inferior à dos/as trabalhadores/as "empregados/as" (24,7\%), têm maior jornada semanal de trabalho $(7,5 \%)$ e menor tempo de permanência no emprego $(53,5 \%)$, ocasionando, dessa forma, aumento de rotatividade com consequente diminuição da possibilidade de continuidade e sentido no trabalho.

Segundo Mandarini, Alves e Sticca (2016), foram observados impactos negativos na saúde de trabalhadores/as "terceirizados/as", devido a fatores no processo de trabalho que desencadearam estresse, doenças relacionadas ao trabalho, riscos de acidentes, falta de suporte à saúde e à segurança, adoecimento psíquico, insegurança e esvaziamento do sentido atribuído ao trabalho. Ademais, também foram encontrados artigos que mostraram forte relação entre a precarização do trabalho e a "terceirização", caracterizada por diferenças salariais e de benefícios, perda dos direitos trabalhistas, excesso de trabalho e falta de treinamento.

Com relação à administração de equipamentos públicos realizada por organizações privadas, alguns estudos, principalmente na área da saúde, destacam fatores positivos dessa modalidade de gestão, como a autonomia de decisão e a descentralização (Barbosa \& Elias, 2010; Ibañez et al., 2001). Entretanto, outros estudos indicam ser este um caminho de diminuição da qualidade do trabalho, ruptura do sentido do trabalho para os/as trabalhadores/as e precarização das condições de trabalho (Lacaz, 2007; Ribeiro, 2014). 
Dado esse contexto, cabe, aqui, fazermos um breve esclarecimento conceitual. Empregamos as expressões "terceiro", "terceirização" e "terceiro setor" entre aspas para assinalar que são termos problemáticos, no sentido de que seu uso promove debates e disputas no campo acadêmico. Montaño (2010), por exemplo, entende que o uso dessas noções possui uma funcionalidade no processo de reestruturação do capital, na medida em que se referem "ao afastamento do Estado das suas responsabilidades de respostas às sequelas da "questão social'” (p. 16). Na mesma direção, Yamamoto (2007) afirma que o recorte em três setores introduz um "atendimento segmentado, com oferta de serviços de qualidade diferenciada conforme a capacidade de pagamento do usuário" (p. 33).

Esses autores criticam, ainda, o fato de o termo "terceiro setor" ser pouco preciso, podendo ser usado para se referir a muitos tipos de organizações diferentes. Além disso, poderíamos nos perguntar se ele pode ser aplicado a uma política social. Afinal, se entendemos "terceirização" como a transferência a terceiros de atividades de apoio, de modo que o Estado possa concentrar todos os seus esforços em sua atividade vocacional (Girardi, 1999), uma política pública não poderia (ou não deveria) jamais ser terceirizada, já que a criação e implementação de políticas públicas não é atividade secundária, mas uma das funções fundamentais do Estado. Soma-se a isso o fato de que o termo "terceirização" surge para falar da transferência de atividades as quais não eram feitas de maneira correta ou que tinham custo muito alto, mas muitos dos serviços do SUAS, que convencionamos a chamar de "terceirizados", nunca foram executados pelo Estado (Cordeiro \& Sato, 2017). A despeito dessas críticas e limitações, neste texto, optamos por usar o termo "terceirização" e seus correlatos, uma vez que fazem parte da linguagem cotidiana dos/as trabalhadores/as da assistência social.

No contexto de São Paulo, a esmagadora maioria dos/as trabalhadores/as que atuam nessa política pública não possui vínculo direto com o Estado. Como apontado anteriormente, tal situação vai na contramão do que está presente na Constituição de 1988 , bem como nas normativas do SUAS. A Norma Operacional Básica de Recursos Humanos do SUAS - NOB-RH/SUAS (Brasil, 2011 a) é clara ao estabelecer que, em consonância com a Constituição Federal de 1988, a execução de tarefas pertinentes ao ente público deve ser precedida de concurso público. Além disso, a normativa salienta que a assistência social é um direito de todos/as e dever do Estado. 
No município de São Paulo, trabalhadores/as do SUAS que servem em equipamentos de administração direta, mas que são regidos pelas OSC "terceirizadas", relacionam-se cotidianamente com os/as "concursados/as". Apesar de haver políticas e normas que regem as práticas de ambas as instituições, há lógicas organizacionais que podem se distinguir na materialização dessas práticas. Diante disso, a presente pesquisa visou identificar e compreender a relação entre trabalhadores/as "contratados/as" e "concursados/as", enfocando as consequências dessas relações para o exercício profissional.

A pesquisa foi realizada em um CRAS, um CREAS e um Núcleo de Proteção Jurídico Social e Apoio Psicológico (NPJ) de uma região da capital paulista, em 2016 e 2017. Sobre os equipamentos acessados, o CRAS é responsável pela organização e oferta de serviços da proteção social básica no território em que está localizado. Suas ações visam "prevenir a ocorrência de situações de vulnerabilidades e riscos sociais nos territórios, por meio do desenvolvimento de potencialidades e aquisições, do fortalecimento de vínculos familiares e comunitários, e da ampliação do acesso aos direitos de cidadania" (Brasil, 2009, p. 9). O CREAS, por sua vez, é o serviço de referência da proteção social especial, sendo esta voltada a famílias e pessoas que estão em situação de risco pessoal ou social, por violação de direitos (Brasil, 2011 b).

Por se tratar de um serviço que existe apenas em São Paulo, esclarecemos que o NPJ destina-se a acompanhar famílias e indivíduos em situação de risco e violação de direitos (SMADS, 2010). Gerido por uma OSC conveniada à prefeitura de São Paulo, o NPJ localiza-se dentro do espaço físico do CREAS, possui capacidade para atender até 120 famílias e uma equipe técnica semelhante à que está prevista para o CREAS. As diretrizes para seu trabalho social estão embasadas no Programa e Atendimento Especializado a Famílias e Indivíduos (PAEFI).

\section{Método}

Foi realizado contato telefônico com três serviços de assistência social, explicando a proposta da pesquisa, mas apenas um mostrou interesse em colaborar com o trabalho. Realizamos uma conversa preliminar com trabalhadores/as e gerentes do serviço, a fim de esclarecer os objetivos do trabalho, bem como obter a autorização institucional. A partir do consentimento da instituição, foi solicitada a indicação de profissionais, com os/as quais, em um 
segundo momento, entrou-se individualmente em contato para a realização do convite e agendamento de entrevistas.

Contamos com a técnica da "bola de neve", ou seja, participantes da pesquisa e gestores/as do equipamento selecionado indicaram pessoas para contribuírem com a pesquisa (do mesmo e de outros serviços) e essas, por sua vez, indicaram outros/as possíveis participantes. A utilização dessa técnica de cadeias de referência possibilitou que acessássemos indivíduos do grupo de interesse rapidamente até atingirmos o "ponto de saturação", isto é, momento em que os objetivos propostos foram alcançados, com a repetição de conteúdos já obtidos em entrevistas anteriores, sem o acréscimo de novas informações relevantes à pesquisa (World Health Association, 1994). A seleção dos/as participantes teve como critério de inclusão estar trabalhando em equipamentos de assistência social do mesmo território. Todos/as os/as colaboradores/as assinaram um Termo de Consentimento Livre e Esclarecido antes da realização do trabalho de campo e consentiram em relação à gravação das entrevistas. Foram realizadas, ao todo, seis entrevistas, sendo que cinco participantes $(83,33 \%)$ eram mulheres e um era homem (16,66 \%). 2 (33,33\%) tinham entre $20-30$ anos, $3(50 \%)$ entre $31-50$ anos e $1(16,66 \%)$ mais que 51 anos. 3 (50\%) trabalhavam na assistência social havia menos de cinco anos, 1 (16,66 \%) entre seis e dez anos e 2 (33,33\%) havia mais de dez anos. 3 (50\%) eram "contratados/as" e 3 (50\%) "concursados/as". 3 (50\%) eram psicólogos/as, 2 (33,33\%) eram assistentes sociais e 1 (16,66 \%) era pedagogo/a. A fim de garantir o sigilo de suas identidades, a referência a todos/as os/as entrevistados/as se dará por meio de nomes fictícios.

\section{Instrumentos}

As entrevistas foram semiestruturadas. Desse modo, foram pautadas por um roteiro previamente estabelecido, contendo tópicos flexíveis e perguntas abertas, a fim de acessar experiências relacionadas às trajetórias profissionais e ao ambiente de trabalho atual, bem como os significados e sentidos atribuídos ao mesmo, sendo exploradas, com perguntas adicionais, semelhanças e diferenças entre ser contratado/a e ser concursado/a para a atuação em equipamentos públicos de assistência social. Fizeram parte desse roteiro questões do tipo: Como 
é trabalhar no (nome do serviço)? Como você vê o trabalho desenvolvido pela OSC e pelos/as servidores/as concursados/as?

Todas as entrevistas foram transcritas integralmente e, após isso, foi realizada a transcrição sequencial de cada uma delas, isto é, um resumo das entrevistas a partir da síntese de cada fala dos/as interlocutores/as, inspirado na proposta de Spink (2010). Ademais, foi realizada a leitura flutuante individualizada de cada uma das transcrições, uma análise vertical (identificação dos temas centrais de cada entrevista e das principais unidades de registro, expressas por frases ou ideias extraídas das entrevistas) e análise horizontal (definição de indicadores a partir do agrupamento de temas comuns às entrevistas e análise de conteúdo relacionada aos objetivos da pesquisa focada nos aspectos relativos ao cotidiano de trabalho, bem como os significados e sentidos atribuídos ao mesmo, com foco nas principais semelhanças e diferenças entre ser concursado/a e ser contratado/a para atuação em equipamentos públicos de assistência social).

Dado o tempo para a realização do estudo, não foi possível que entrássemos em contato com outros serviços e regiões da capital paulista, sendo essa uma limitação da pesquisa. Assim, os resultados não podem ser generalizados para o contexto de São Paulo, tampouco para a conjuntura nacional. Entretanto, buscamos articular os achados com o que coletivamente vem sendo produzido em estudos sobre "terceirização" no trabalho contemporâneo, sobretudo no campo da assistência social.

\section{Discussão}

A cidade de São Paulo é um dos exemplos, senão o maior, no Brasil, de intensa relação público-privada na operacionalização de políticas sociais. No contexto da assistência social, mesmo em um serviço operado diretamente, o CREAS, encontramos o NPJ. Em suma, sob o argumento de inviabilidade de realização de concursos públicos-sobretudo para psicólogos/as e advogados/as, já que a legislação municipal não prevê a contratação desses/as profissionais para atuar na assistência social-, os NPJs constituem uma estratégia de gestão para atender precariamente o quadro de profissionais necessários para alcançar os objetivos do PAEFI. Além de estar em discordância com as normativas da política (Brasil, 2005, 2009, $2011 \mathrm{a}, 2011 \mathrm{~b}$ ) - que determinam que o PAEFI seja executado diretamente por uma unidade estatal, o CREAS -, os NPJ's 
apresentam vínculos trabalhistas frágeis, sobretudo pela limitação temporal dos convênios firmados.

A rara existência de um plano de carreira dentro das OSC, bem como a escassez de benefícios adicionais são alguns dos motivos pelos quais todos/as os/as trabalhadores/as contratados/as que participaram deste estudo afirmaram pensar em mudar de área de atuação. Em contrapartida, o serviço público foi relacionado à estabilidade, a maiores e a melhores benefícios: licenças, férias, bonificações e, sobretudo, à possibilidade de contribuir para transformações sociais (não ficando claro o que se entende por esta expressão). A fala de Beatriz, uma das trabalhadoras entrevistadas, é ilustrativa:

Eu acho que se foi o tempo em que as pessoas iam procurar o serviço público por garantia de emprego. O que eu vejo hoje com as pessoas que eu me relaciono, eu vejo que tem uma vontade de fazer certo, uma vontade de servir, uma vontade de crescer, uma vontade de participar e não ficar naquele... fazer diferença mesmo, mudar esse paradigma negativo de um funcionário público. (Beatriz, trabalhadora concursada)

Notou-se que o aspecto da vontade em ser um agente de transformação social estava presente tanto no discurso dos/as funcionários/as concursados/as quanto dos/as contratados/as. Tal aspecto foi fortemente relacionado ao trabalho no setor da assistência social e no campo das políticas públicas, mesmo que em serviços públicos não estatais, como é o caso dos serviços geridos pelas OSC.

Além de ressaltar a relevância social de seu trabalho, os/as entrevistados/as diferenciaram a atuação no setor privado (empresas) daquela que ocorre no "terceiro setor". Apesar de, em termos de direitos trabalhistas, as condições serem similares - regime de trabalho CLT -, o valor dos salários, a hierarquia, os benefícios e o sentido do trabalho são vistos como diferentes. Segundo os/as entrevistados/as, a iniciativa privada paga melhores salários, oferece melhores benefícios (plano de saúde, vale alimentação, vale refeição) e plano de carreira, mas apresenta um alto grau de hierarquia, o que foi apontado como um aspecto negativo. Além disso, o objetivo/sentido do trabalho mostrou-se distinto, uma vez que, na iniciativa privada, vigora a cobrança por produtividade e a sensação de que se é mais um número dentro da empresa, alguém que pode ser facilmente substituído e não um/a funcionário/a qualificado/a. Ademais, o trabalho 
no setor privado foi associado à entrega de um produto, isto é, independentemente das necessidades encontradas, são adotadas medidas padronizadas.

No setor público, seja pela administração direta ou indireta, os/as trabalhadores/as relataram que o trabalho está voltado para os interesses dos/as usuários/as e que, a despeito de muitos desafios para a efetivação da política de assistência social, o atendimento se dá de modo personalizado, considerando os contextos das pessoas atendidas. A visão exposta pelos/as entrevistados/as sobre a iniciativa privada, no entanto, é de o foco estar localizado nos interesses da empresa e o "produto" estar menos articulado com as necessidades da população atendida. Vale reiterarmos que o sentido atribuído ao trabalho no setor público e no "terceiro setor" foi equiparado pelos/as entrevistados/as, enquanto agentes de transformação social.

Apesar da padronização do trabalho não ter sido reconhecida entre os/as entrevistados/as como questão, a apresentação de resultados a partir de metas pré-estabelecidas foi apontada como uma dificuldade pelos/as trabalhadores/as contratados/as, na medida em que a atenção a essa demanda refere-se, na maior parte das vezes, a um quantitativo e não à qualidade do trabalho desenvolvido. O MROSC (Brasil, 2014) foi um avanço na visão dos/as trabalhadores/as concursados/as, pois regulou a contratação das OSC - com etapas de procedimento de manifestação de interesse social, plano de trabalho, chamamento público, contratação, liberação dos recursos, aplicação e execução, monitoramento e avaliação, prestação de contas-, no entanto, por outro lado, na visão dos/as mesmos/as, centra-se no atendimento de metas e resultados.

A política de controle gerida pelo Estado para fiscalizar as OSC, além de não garantir a qualidade do serviço, interfere negativamente no mesmo, pois burocratiza processos. Aguilar Lara (2019), ao estudar a implementação do MROSC no município de São Paulo, identificou que, apesar do documento buscar a desburocratização e padronização das parcerias, a forma como foi conduzida sua concretização causou desconfiança entre trabalhadores/as, sobretudo devido a uma relação com o poder público "distante, pouco dialógica e por vezes impositiva" (p. 159).

Os relatos dos/as servidores/as concursados/as que participaram deste estudo vão na mesma direção de Raichelis (2010). Eles/as expressaram grande insatisfação com a entrada de OSC para a execução das ações previstas na PNAS (2004). Afinal, consideram que essa entrada está associada à "terceirização" do serviço público e das responsabilidades estatais, no que tange à garantia de direitos da população. O trabalho das OSC é visto, no geral, como adequado, uma 
vez que os serviços seguem as prerrogativas da política. A supervisão, realizada pelos/as funcionários/as concursados/as dos CRAS e CREAS em todos os serviços conveniados, apareceu nas falas dos/as concursados/as como um espaço de fiscalização, correção de inadequações, avaliação, mas, também, de discussão de casos. Sobre isso, é necessário pontuar que, no momento de realização da pesquisa, os/as concursados/as cuidavam da supervisão técnica dos serviços conveniados e da prestação de contas. Já os/as profissionais contratados/as ficavam em contato direto com o público, realizando atendimentos, visitas domiciliares, atividades etc, com exceção do/a gerente do serviço. Aqui, observamos uma demarcação clara de quem exerce funções administrativas e executivas na política pública, nesse contexto. Também desprendemos das entrevistas que a relação Estado-OSC é complexa, plural e multifacetada, não cabendo uma dicotomia simplista "Estado bom" e "OSC ruim".

Assim, se por um lado discutimos a privatização de serviços públicos e a transferência das responsabilidades estatais à sociedade civil (Yamamoto, 2007), por outro, observamos uma cisão no campo da execução e efetivação das políticas sociais, na garantia de direitos da população e também dos/as próprios/as trabalhadores/as do SUAS. Apesar de todos/as os/as entrevistados/as frisarem em suas falas a garantia de direitos como foco principal de suas práticas, percebemos que há uma oferta diferente de serviços, mesmo que pautados numa mesma política. Oferta esta atravessada pelo atendimento a metas, pelas constantes incertezas se os contratos serão ou não renovados, mas também pelo distanciamento das funções exercidas por trabalhadores/as contratados/as e concursados/as, tornando-se difícil a comparação direta entre os processos de trabalho. Tal contexto aproxima-se do que Ribeiro (2014) chama de flexibilização legal e contratual, na medida em que há uma diversidade de como o serviço é prestado.

Outra questão que surgiu nas entrevistas foi a hierarquia como central na organização do trabalho e das relações entre concursados/as e contratados/as. Hierarquia esta que foi trazida sob dois vieses: (1) positivo, no sentido de a coordenação conversar entre si antes de ser comunicado algo, mesmo quando o assunto é relacionado à equipe técnica da OSC ou do CRAS/CREAS. Assim, evita-se a transmissão direta de orientações entre, por exemplo, coordenador/a de CREAS e equipe técnica do NPJ, sendo necessária a mediação da coordenação da OSC. O aspecto positivo destacado se dá na medida em que se evita uma "dupla chefia" e o processo é reconhecido como um facilitador da comunicação. (2) Negativo, hierarquia como oposto de parceria. Tal aspecto foi 
levantado, sobretudo, pelos/as funcionários/as contratados/as, os/as quais destacaram que a política postula que haja a parceria entre Estado e OSC, mas que, na prática, muitas vezes, o que se vê é fiscalização, abuso de poder e imposições dos/as funcionários/as estatais em relação aos/às profissionais contratados.

[...] apesar de no discurso ser uma parceria, na prática estamos subordinados a eles [...] a questão de estarmos dentro do prédio público interfere muito nisso também, porque quando são serviços separados, a gente percebe que eles têm mais autonomia para fazer o que eles precisam fazer. (Alice, trabalhadora contratada)

Em referência a essa questão, foi relatado por um/a profissional perseguições e assédio moral sofridos dentro e fora do ambiente de trabalho. Esse caso gerou um processo administrativo que está tramitando nas instâncias secretariais.

Os/as funcionários/as contratados/as destacaram, por diversas vezes, a sensação de não serem bem quistos/as. Apesar de entenderem a resistência em aceitar a execução da política por uma OSC por parte dos/as concursados/as, a partir do momento em que existe essa parceria, a expectativa é que haja um trabalho em conjunto. Nesse sentido, relataram que se sentem pressionados/as pelos dois lados: institucionalmente e pela população, visto que são eles/as que atuam diretamente com o público e recebem as demandas, bem como as críticas.

Os/as entrevistados/as relataram, ainda, que a política pública está sendo cuidada e efetivada e que, para a população, a cisão entre os/as trabalhadores de acordo com seus vínculos empregatícios não aparece, sendo todos/as identificados/as como representantes do Estado. Afinal, a eliminação do vínculo formal não altera o conteúdo do cargo desempenhado, ao contrário, o/a trabalhador/a desempenha a mesma função, porém, em piores condições.

Três entrevistados/as sustentaram também que o Estado não está efetivamente na linha de frente na entrega dos serviços à população, havendo uma desresponsabilização do mesmo, além de uma sobrecarga do trabalho desenvolvido pelas organizações. A questão que seus depoimentos nos trazem é: no limite, a quem e por quem os/as trabalhadores/as contratados/as respondem: ao Estado ou à OSC?

A literatura nos oferece diferentes respostas a essa inquietante questão. Até mesmo o nome dado à relação Estado-sociedade civil varia de acordo com a posição adotada pelos/as autores/as. Aqueles/as que defendem que há desresponsabilização costumam considerar que 
essa se dá atrelada ao avanço do neoliberalismo e à defesa do "Estado mínimo". Outros/as chamam essa relação de "terceirização", uma vez que consideram que o Estado delega a "terceiros" (às OSC) a execução de serviços que, por princípio, são de sua responsabilidade. Há ainda aqueles/as que afirmam que as OSC perdem autonomia ao se submeterem às regras do Estado, enquanto que outros/as defendem que a relação Estado-sociedade civil é pautada por um processo de corresponsabilização e regulação das políticas públicas, "afirmando a possibilidade da construção de uma rede de caráter público com a participação de instituições estatais e nãoestatais" (Aguilar Lara, 2019, p. 20). Independentemente de como nomeiam ou classificam essa relação, os/as contratados/as afirmaram perceber que há uma superioridade associada a ser funcionário/a público/a, reiterando a presença constante de uma hierarquia entre Estado e OSC. "As relações não são simétricas e muito menos igualitárias, mas em distintos níveis existem relações desiguais de poder que permeiam os espaços de interação e diálogo entre as OSC e o Estado" (Aguilar Lara, 2019, p. 122).

No caso dos serviços visitados, essa hierarquia ganha um novo contorno: os/as servidores/as concursados/as, no geral, estão no serviço público há mais de 20 anos. Surgiu, então, a questão da experiência versus enrijecimento ("aceitação do sistema"). Isto é, a experiência desses/as profissionais com o trabalho em políticas públicas e em termos históricos da construção da política de assistência social no município foi apontada como um aspecto positivo nas relações de trabalho, em contrapartida, por vezes, tal experiência, segundo os/as funcionários/as contratados/as, aparece como uma regra, "o sistema é assim, sempre foi assim", fechando, muitas vezes, o caminho para outras possibilidades de articulação. Em contrapartida, observamos que os/as contratados/as eram mais jovens, tendo a maioria cinco anos de formado/a e já tinham passado por mais de um serviço da própria OSC.

Nesse sentido, observamos acima uma clivagem entre trabalhadores/as contratados/as e concursados/as, que explicita a heterogeneidade de vínculos empregatícios e regimes de trabalho na morfologia do trabalho contemporâneo, mas também os impactos dessa miscelânea administrativa nas relações de trabalho cotidianas. Em contrapartida, como um ponto de consenso, tanto os/as funcionários/as concursados/as quanto os/as contratados/as ressaltaram, por diversas vezes, a importância de a seguridade social ser encarada como um direito dos/as cidadãos/ãs; porém, apenas metade deles/as destacou que ela é, também, dever do Estado. A 
política de assistência social foi elogiada, principalmente, em termos de seu avanço teóricoconceitual, combatendo visões tradicionais nesse campo, como a noção de caridade.

No entanto, os/as trabalhadores/as contratados/as, quando questionados se tinham perspectiva de continuar trabalhando na assistência social, todos/as afirmaram que não. Alguns dos motivos elencados foram: (1) o caráter do trabalho, apesar de verem sentido em sua atuação, as dificuldades diárias com a falta de recursos e serviços na rede, bem como a baixa taxa de casos mostram resultados exitosos, são frustrantes e geradores de sofrimento nos/as profissionais; (2) as relações institucionais, confirmando o que a literatura traz (Mandarini, Alves, \& Sticca, 2016), isto é, diferenças de tratamento, salariais e de benefícios, excesso de trabalho e falta de plano de carreira; (3) o interesse em trabalhar em outros setores, como na saúde, ou tornar-se um/a profissional liberal. Nesse sentido, alguns/mas destacaram que o trabalho na assistência social não foi planejado, sendo uma oportunidade de primeiro emprego após a conclusão da graduação.

Assim, apesar de o sentido do trabalho estar "assegurado", isto é, o interesse e a vontade de promover transformações sociais por meio do trabalho em serviços públicos - seja como servidor/a concursado/a ou contratado/a-, identificamos que os/as trabalhadores/as contratados/as sofrem pressão por, no mínimo, quatro instâncias: a "institucional em relação aos/às servidores/as públicos/as" que os/as negam cotidianamente, explicitando motivos pelos quais não deveriam estar ocupando aquelas funções, uma vez que se entende tal prestação de serviço como "terceirização" das responsabilidades estatais; a "institucional em relação à organização para as quais trabalham", visto que os convênios com a Prefeitura exigem frequente prestação de contas, alcance de metas e justificativas sobre o que foi produzido; "relacional com o público atendido", visto que são reconhecidos/as como representantes do Estado e, portanto, cobrados/as como tais, mesmo não sendo efetivamente, condição que gera ambiguidade; e a“judicial", por meio de exigências de geração de resultados milagrosos, em prazos curtos, para demandas complexas.

Em relação à organização empregadora, não foi tecida nenhuma crítica direta a ela. Inclusive, os/as profissionais contratados/as, apesar de reconhecerem que há vários tipos de OSC atuando em São Paulo e que muitas delas não realizam um trabalho de qualidade, referiram-se à sua empregadora como uma organização séria e comprometida com a questão social, visto que está articulada com movimentos populares desde sua fundação. Ademais, falaram positivamente 
do suporte dado a eles/as como funcionários/as, afirmando que os/as dirigentes das mesmas são presentes em seu cotidiano.

Mesmo assim, dois/duas entrevistados/as contratados/as destacaram seu interesse em haver concursos públicos para os cargos que ocupam, podendo, dessa forma, ter mais respaldo institucional para suas ações, maior estabilidade, além de melhor remuneração e melhores benefícios. Nesse sentido, é importante destacar que, de acordo com os/as entrevistados/as, há variabilidade de salários e benefícios entre as OSC, configurando, por vezes precarização, instabilidade e insegurança nas relações de trabalho, efeitos sublinhados por Marcelino (2008); assim como ampliando ainda mais as diferenças entre os regimes estatutário e celetista no interior dos serviços públicos e, portanto, também entre os/as trabalhadores/as.

A estabilidade no emprego é importante para o/a trabalhador/a, uma vez que permite com que possa fazer planos no campo profissional e pessoal, diminui inseguranças e ansiedades. Mas é fundamental, também, para a qualidade do serviço ofertado. Afinal, favorece a construção da identidade de trabalhador/a da política, já que possibilita a perspectiva de permanência na área. Diminui a rotatividade, evitando desperdício de tempo e dinheiro com formação continuada e preservando saberes construídos a partir da experiência (Cordeiro \& Sato, 2017). Além disso, permite que servidores/as públicos/as possam exercer sua função sem sofrerem interferência de interesses específicos dos diferentes grupos que assumem o poder, e sem que necessitem exercer atividades em instituições privadas concomitantemente ao trabalho na administração pública. "Em suma, visam garantir a execução das políticas de Estado e não apenas de planos de governos que se alternam" (Cordeiro et al., 2019, p. 335, tradução nossa).

Apesar de garantir maior estabilidade e melhores condições de trabalho, a relação que surge após o concurso público não está isenta de questionamentos e problematizações.

[...] a questão do RH [recurso humano] ainda é bastante problemática. Quer dizer, se você tem funcionários públicos, o fato de você ter uma situação estável e tudo mais, também te possibilita em ter muitas licenças médicas, muitas desistências, muitas férias, então, é preciso ajustar um pouco o mecanismo de como você faz essa implementação". Por outro lado, quando há "terceirização", "você tem um nível de comando diferente e você tem muita rotatividade de pessoas, muito mais que no serviço público, porque poucas OS [organizações sociais] têm carreiras e o município não paga carreira, ela paga um salário 
básico. Se a OS tem carreira, ela tem que fazer captação de recursos próprio. (Claudia, trabalhadora concursada)

Apesar das diferenças de contratação saltar aos olhos, o que fica claro é que, com a contrarreforma Bresseriana e com a aprovação do MROSC, o Estado aposta na transferência da execução de serviços públicos ao "terceiro setor", em vez de colocar em discussão e investir na modernização de processos de gestão da administração pública para lidar com a dita "ineficiência", as amarras burocráticas, a não qualificação dos/das servidores/as e falta de qualidade nos serviços prestados (Santos, 2006). A ilusão de que a "solução" para as mazelas estatais encontra-se fora do Estado, no "terceiro setor" ou mesmo na iniciativa privada, por vezes pode invisibilizar questões relacionadas à qualidade, eficiência e economicidade tão exaltadas pelo neoliberalismo.

Nesse sentido, foram apontados desafios, tanto por contratados/as quanto por concursados/as, para a efetivação da política de assistência social, que transcendem as questões relacionadas aos recursos humanos, tais como: a oferta de serviços na rede socioassistencial (relacionada também ao subfinanciamento da pasta), a institucionalização das relações intersetoriais (sobretudo com a saúde) e a relação com o Poder Judiciário. Tais desafios afetam os serviços de administração direta e indireta, sendo assim, "compreendemos que a 'desresponsabilização' está associada à centralidade que a assistência social ocupa (ou, no caso, não ocupa) na agenda governamental, e não apenas do desenho institucional de uma rede socioassistencial mista" (Aguilar Lara, 2019, p. 45).

\section{Conclusões}

A partir da pesquisa realizada, observamos que, como mostra a literatura, a "terceirização" de equipamentos públicos é uma forma de ofertar, por vezes, serviços precarizados e híbridos à população, bem como tem implicações severas nos direitos de trabalhadores/as e nas relações de trabalho cotidianas. Apesar disso, trabalhos sobre os efeitos da "terceirização" em equipamentos de assistência social ainda são incipientes e essas questões precisam ser melhor investigadas no contexto de São Paulo, mas também em outros municípios e regiões, visto que esse modelo desponta como uma das tendências no atual mundo do trabalho. 
Primeiramente, faz-se necessário marcar que a relação entre profissionais concursados/as e contratados/as é complexa, plural e multifacetada, não cabendo uma dicotomia simplista "Estado bom" e "OSC ruim", ou vice versa. Tanto profissionais concursados/as quanto contratados/as apontaram que o sentido maior do seu trabalho está em ser um agente de transformação social, mas que vários fatores dificultam ou possibilitam a realização plena de seu trabalho.

Em termos das relações de trabalho, por meio desta pesquisa, foi possível verificar que há, a todo o momento, uma clara separação e hierarquia entre os/as profissionais com base em sua forma de contratação, o que dificulta a configuração de uma equipe articulada e, por vezes, a própria execução das diretrizes da política.

Ambas as modalidades de vínculo de trabalho indicaram um movimento de privatização do público e a forma de contratação é um dos elementos desse processo que, de um lado, foca mais no cumprimento de metas predefinidas do que na atenção às necessidades expressas pela população e, de outro lado, ao flexibilizar as formas de contratação, podem precarizar as condições de trabalho tanto de concursados/as, quanto de contratados/as. Dessa forma, torna-se relevante avaliarmos os impactos das decisões administrativas macroestruturais, como as de caráter municipal, nas relações microestruturais (nos equipamentos de assistência social, na relação destes com a população, por exemplo), a fim de podermos argumentar qualitativamente acerca de mudanças estruturais e colaborar para a formulação de políticas públicas condizentes com as necessidades da população e dos/as trabalhadores/as do SUAS.

Assim, vale retomar que a Constituição Federal de 1988, a LOAS e a PNAS preveem a execução da assistência social com a participação de OSC. Contudo, a relação com essas organizações deve integrar a rede de serviços socioassistenciais, de modo que não se perca o caráter de comando único estatal na política de assistência social. O que atualmente ocorre em São Paulo, entretanto, é uma discrepância em relação à proporção de serviços conveniados e serviços prestados de modo direto pelo órgão municipal. Além disso, a prevista "parceria" se dá na prática mais como uma relação fiscalizatória, o que deturpa o aspecto de cooperação entre Estado e sociedade civil e instaura, em contrapartida, disputas e assimetrias na execução da política de assistência social e no que concerne a direitos dos/as trabalhadores/as e nas relações de trabalho entre profissionais concursados/as e contratados/as do SUAS. 


\section{Referências}

Aguilar Lara, M. F. (2019). A implementação do Marco Regulatório das Organizações da Sociedade Civil (MROSC) na assistência social do município de São Paulo: uma análise dos discursos de profissionais do SUAS [Dissertação de mestrado não publicada]. Universidade de São Paulo.

Antunes, R. (2005). O caracol e sua concha: ensaios sobre a nova morfologia do trabalho. São Paulo: Boitempo Editorial.

Antunes, R. (2012). A nova morfologia do trabalho no Brasil: reestruturação e precariedade. Nueva Sociedad, 44-59. https://static.nuso.org/media/articles/downloads/3859_1.pdf

Barbosa, N. B., \& Elias, P. E. M. (2010). As organizações sociais de saúde como forma de gestão público/privado. Ciência \& Saúde Coletiva, 15(5), 2483-2495. https://doi.org/10.1590/S1413-81232010000500023

Brasil, República Federativa do Brasil. (1943). Decreto-lei $n^{\circ} 5.452$, de $1^{\circ}$ de maio de 1943. Aprova a Consolidação das Leis do Trabalho. Brasília, DF: Presidência da República. http://www.planalto.gov.br/ccivil_03/decreto-lei/del5452.htm

Brasil, República Federativa do Brasil. (1988). Constituição da República Federativa do Brasil de 1988. Brasília, DF: Presidência da República. http://www.planalto.gov.br/ccivil_03/constituicao/constituicao.htm

Brasil, República Federativa do Brasil. (1990). Lei $n^{\circ}$ 8.112, de 11 de dezembro de 1990. Dispõe sobre o regime jurídico dos servidores públicos civis da União, das autarquias e das fundações públicas federais. Brasília, DF: Presidência da República. http://www.planalto.gov.br/ccivil_03/leis//8112cons.htm

Brasil, República Federativa do Brasil. (1999). Lei nº 9.790, de 23 de março de 1999. Dispõe sobre a qualificação de pessoas jurídicas de direito privado, sem fins lucrativos, como Organizações da Sociedade Civil de Interesse Público, institui e disciplina o Termo de Parceria, e dá outras providências. Brasília, DF: Presidência da República. http:/ /www.planalto.gov.br/ccivil_03/Leis/L9790.htm 
Brasil, República Federativa do Brasil. (2014). Lei $n^{\circ}$ 13.019, de 31 de julho de 2014. Estabelece o regime jurídico das parcerias entre a administração pública e as organizações da sociedade civil, em regime de mútua cooperação. Brasília, DF: Presidência da República. http://www.planalto.gov.br/ccivil_03/_ato20112014/2014/lei/I13019.htm

Brasil, República Federativa do Brasil. Ministério do Desenvolvimento Social e Combate à Fome. Secretaria Nacional de Assistência Social. (2005). Política Nacional de Assistência Social PNAS/ 2004. Norma Operacional Básica NOB/SUAS. Brasília, DF: MDS. http://www.mds.gov.br/webarquivos/publicacao/assistencia_social/Normativas/PNAS2 004.pdf

Brasil, República Federativa do Brasil. Ministério do Desenvolvimento Social e Combate à Fome. (2009). Orientações Técnicas Centro de Referência de Assistência Social - CRAS. Brasília, DF: MDS.

Brasil, República Federativa do Brasil. Ministério do Desenvolvimento Social e Combate à Fome. (2011a). Norma Operacional Básica de Recursos Humanos do SUAS: NOBRH/SUAS. Brasília, DF: MDS.

Brasil, República Federativa do Brasil. Ministério do Desenvolvimento Social e Combate à Fome. (2011b). Orientações Técnicas Centro de Referência Especializado de Assistência Social - CREAS. Brasília, DF: MDS.

Brasil, República Federativa do Brasil. Ministério do Desenvolvimento Social e Combate à Fome. (2018). Censo SUAS 2017: análise dos componentes sistêmicos da política nacional de assistência social. Brasília, DF: MDS.

Cordeiro, M. P., \& Sato, L. (2017). Psicologia na política de assistência social: trabalho em "setor terceirizado". Estudos de Psicologia, 34(1), 41-52. https:// doi.org/10.1590/1982-02752017000100005

Cordeiro, M. P., Sato, L., \& Oliveira, F. (2019). Outsourcing and the growing precarity of psychologists' work in social services in Brazil: repercussions for subjectivities. Subjectivity, 12(4), 333-351. https://doi.org/10.1057/s41286-019-00078-5

Costa, J. F. A. (2016). Cidadania, reconhecimento e proteção social: um estudo sobre serviços socioassistenciais na cidade de São Paulo [Dissertação de Mestrado, 
Universidade de São Paulo]. Biblioteca Digital de Teses e Dissertações da USP. https://doi.org/10.11606/D.47.2017.tde-08022017-100738

Girardi, D. M. (1999). A importância da terceirização nas organizações. Revista de Ciências da Comunicação, 1(1), 23-31.

Ibañez, N., Bittar, O. J. N. V., Sá, E. N. D. C., Yamamoto, E. K., Almeida, M. F. D., \& Castro, C. G. J. D. (2001). Organizações sociais de saúde: o modelo do Estado de São Paulo. Ciência \& Saúde Coletiva, 6(2), 391-404. https://doi.org/10.1590/S141381232001000200009

Lacaz, F. A. C. (2007). O campo saúde do trabalhador: Resgatando conhecimentos e práticas sobre as relações trabalho-saúde. Cadernos de Saúde Pública, 23(4), 757-766. https:// doi.org/10.1590/S0102-311X2007000400003

Lima, R. C., \& Curado, M. P. F. (2017). O futuro do Estado no Brasil e seus impactos na sociedade: questões para o desenvolvimento até 2035 (Texto para discussão). Brasília, DF: Instituto de Pesquisa Econômica Aplicada. https://www.ipea.gov.br/portal/images/stories/PDFs/TDs/td_2326b.pdf

Mandarini, M. B., Alves, A. M., \& Sticca, M. G. (2016). Terceirização e impactos para a saúde e trabalho: uma revisão sistemática da literatura. Revista Psicologia: Organizações e Trabalho, 16(2), 143-152. http://doi.org/10.17652/rpot/2016.2.661

Marcelino, P. R. P. (2008). Terceirização e ação sindical: a singularidade da reestruturação do capital no Brasil [Tese de Doutorado, Universidade Estadual de Campinas]. Repositório da Produção Científica e Intelectual da Unicamp. http:/ / www.repositorio.unicamp.br/handle/REPOSIP/280871

Mestriner, M. L. (2008). O Estado entre a filantropia e a Assistência Social (4a ed.). São Paulo: Cortez.

Montaño, C. (2010). Terceiro setor e questão social: crítica ao padrão emergente de intervenção social(6a ed.). São Paulo: Cortez.

Netto, J. P. (1999). FHC e a política social: um desastre para as massas trabalhadoras. In I. Lesbaupin (Org.), O desmonte da nação. Balanço do governo FHC (pp. 75-90). Petrópolis: Vozes. 
Raichelis, R. (2010). Intervenção profissional do assistente social e as condições de trabalho no SUAS. Serviço Social e Sociedade, 104, 750-772. https://doi.org/10.1590/S010166282010000400010

Ribeiro, M. A. (2014). Problemas contemporâneos para a psicologia do trabalho e das organizações. In J. J. Orejuela Gómez (Ed.), Psicología de las organizaciones y del trabajo: apuestas de investigación (pp. 47-78). Cali: Editorial Bonaventuriana.

Santos, L. (2006). Da Reforma do Estado à Reforma da Gestão Hospitalar Federal: Algumas Considerações. Campinas: Instituto de Direito Sanitário Aplicado - IDISA. http://idisa.org.br/img/File/A\%2520gestao\%2520hospitalar\%2520e\%2520a\%2520Refor ma\%2520Administrativa\%2520_versao\%2520CEBES.pdf

Secretaria Municipal de Assistência e Desenvolvimento Social de São Paulo [SMADS]. (2010). Portaria 46/2010/SMADS. Dispõe Sobre a Tipificação da Rede Socioassistencial do Município de São Paulo e a Regulação de Parceria Operada por meio de Convênios. São Paulo: Prefeitura de São Paulo. https://www.prefeitura.sp.gov.br/cidade/secretarias/upload/assistencia_social/arquivos /portarias/portaria_46-2010.pdf

Secretaria Municipal de Assistência e Desenvolvimento Social de São Paulo [SMADS]. (2020). CGPAR/ Relação de Convênios/ Fevereiro 2020. São Paulo: SMADS. https://www.prefeitura.sp.gov.br/cidade/secretarias/upload/RAIO\%20X/2\%20Raio\%20X \%20Fevereiro\%202020.odt

Secretaria Nacional de Relações de Trabalho \& Departamento Intersindical de Estatística e Estudos Socioeconômicos [SRT/DIEESE]. (2014). Terceirização e desenvolvimento: Uma conta que não fecha. Dossiê acerca do impacto da terceirização sobre os trabalhadores e propostas para garantir a igualdade de direitos. São Paulo: CUT. https:// www.cut.org.br/system/uploads/ck/files/Dossie-Terceirizacao-eDesenvolvimento.pdf

Senra, C., \& Guzzo, R. (2012). Assistência social e psicologia: sobre as tensões e conflitos do psicólogo no cotidiano do serviço público. Psicologia \& Sociedade, 24(2), 293-299. https://doi.org/10.1590/S0102-71822012000200006 
Spink, M. J. (2010). Linguagem e produção de sentidos no cotidiano. Rio de Janeiro: Centro Edelstein de Pesquisas Sociais.

World Health Association [WHA]. (1994). Division of Mental Health. Qualitative Research for Health Programmes. Geneva: WHA.

Yamamoto, O. (2007). Políticas sociais, "terceiro setor" e "compromisso social": perspectivas e limites do trabalho do Psicólogo. Psicologia \& Sociedade, 19(1), 30-37. https:// doi.org/10.1590/S0102-71822007000100005

Recebido em: 1/9/2018

Aprovado em: $30 / 4 / 2020$ 